5. Zbar AP, Murphy F, Krishna SM. Adult postoperative intussusception: a rare cause of small bowel obstruction. South Med J. 2007;100:1042-4.

6. Sedgwick CE, Vernon JK. Jejunojejunal intussusception. An unusual complication after pancreatoduodenectomy. Am J Surg. 1970;119:752-3.

7. Duncan A, Phillips TF, Sclafani SJ, Goldstein AS, Lipkowitz G, Scalea TM, et al. Intussusception following abdominal trauma. $J$ Trauma. 1987;27:1193-9.

8. Hunter JG, Schwartz ME, Kim US. Postoperative intussusception after vaginal vault suspension. Am J Obstet Gynecol. 1986;154:633-4.

9. Wu TH, Lin CW, Yin WY. Jejunojejunal intussusceptions following jejunostomy. J Formos Med Assoc. 2006;105:355-8.

10. Wolfson S, Shachor D, Freund U. Ileocolic intussusceptions in an adult. A postoperative complication of appendectomy. Dis Colon Rectum. 1984;27:265-6.

11. Orringer MB, Marshall B, Chang AC, Lee J, Pickens A, Lau CL. Two thousand transhiatal esophagectomies: changing trends, lesson learned. Ann Surgery. 2007;246:363-72; discussion $372-4$.

12. Hulscher JB, Tijssen JG, Obertop H, Van Lanschot JJ. Transthoracic versus transhiatal resection for carcinoma of the esophagus: a meta-analysis. Ann Thorac Surgery. 2001;72:306-13.

13. Hulscher JB, van Sandick JW, de Boer AG, Wijnhoven BP, Tijssen JG, Fockens P, et al. Extended transthoracic resection compared with limited transhiatal resection for adenocarcinoma of the esophagus. N Engl J Med. 2002;347:1662-9.

14. Reymond RD. The mechanism of intussusceptions: a theoretical analysis of the phenomenon. Br J Radiol. 1972;45:1-7.

15. Zahur Hussain, M.A.Bhat, A.G. Ahangar, A.M. Dar, G.N.Lone, Reyaz, et al. Unusual complications of Feeding Jejunostomy, Feeding catheter induced jejuno-jejunal intussusceptions. $J K$ Practitioner. 2006;13:103.

16. Saar MG, Nagorney DM, Mcllrath DC. Postoperative intussusception in adult: a previously unrecognized entity? Arch Surg. 1981;116:144-8.

\section{Role of upper gastrointestinal endoscopy in the treatment of sump syndrome}

\section{Introduction}

Biliary "sump syndrome" is an infrequent complication of sideto-side choledochoduodenostomy (CDD) performed for achieving permanent drainage of common bile duct (CBD). It is associated with recurrent stone formation in about $40 \%$ due to the stenosis of CDD and failure of the dilated CBD to decompress after CDD. Endoscopic retrograde cholangiopancreatography (ERCP) and endoscopic sphincterotomy (ES) is regarded as the treatment of choice for sump syndrome but has a restenosis rate as high as $19 \%$, necessitating repeat papillotomy. We report a case of sump syndrome successfully managed by dilatation of the stenosed CDD using an upper GI endoscope.

\section{Case report}

Biliary "sump syndrome" is an infrequent complication of sideto-side choledochoduodenostomy (CDD) performed for achieving permanent drainage of common bile duct (CBD). ${ }^{1}$

It is associated with recurrent stone formation in about $40 \%$ due to the stenosis of CDD and failure of the dilated CBD to decompress after CDD. ${ }^{2,3}$ Endoscopic retrograde cholangiopancreatography (ERCP) and endoscopic sphincterotomy (ES) is regarded as the treatment of choice for sump syndrome but has a restenosis rate as high as $19 \%$, necessitating repeat papillotomy., ${ }^{4,5}$

A 60-year-old man presented with a history of recurrent cholangitis. He underwent cholecystectomy and side-to-side CDD 10 years back and an ERCP three years back for retained CBD stone due to sump syndrome. Ultrasound abdomen revealed a massively dilated $\mathrm{CBD}$ with multiple $\mathrm{CBD}$ stones and a repeat ERCP was planned. Side viewing scopy failed to show the ampulla but the opening of a partially blocked CDD was seen. The cholangiogram through CDD confirmed the presence of multiple large stones (Figure 1). The opening of CDD was dilated by putting a CRE balloon (microvasive-TTS balloon, 15-18 $\mathrm{mm}$ diameter, $240 \mathrm{~cm}$ length) through an UGI endoscope. After dilatation of CDD the UGI endoscope was negotiated into the biliary tree for removal of stones under vision (Figure 2). The larger fragments were removed by basket and smaller fragments of stones lying in dependent part of the

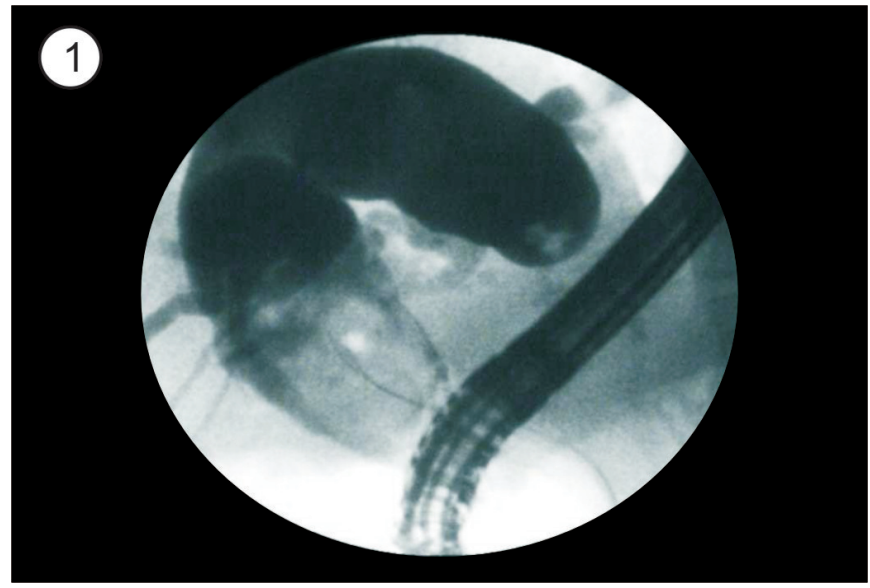

Figure 1: Cholangiogram showing very large stone In CBD 


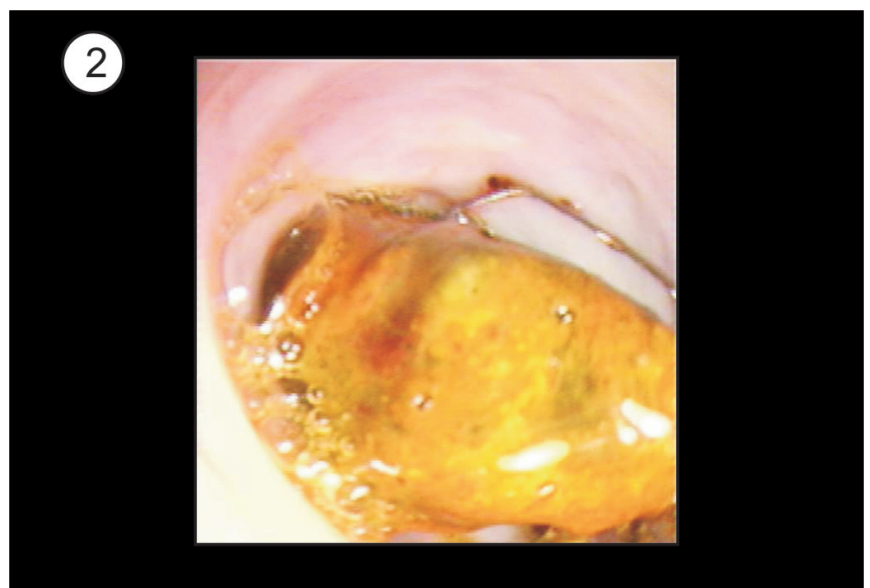

Figure 2: Endoscope introduced through choledochoduodenostomy showing large CBD trapped in a basket

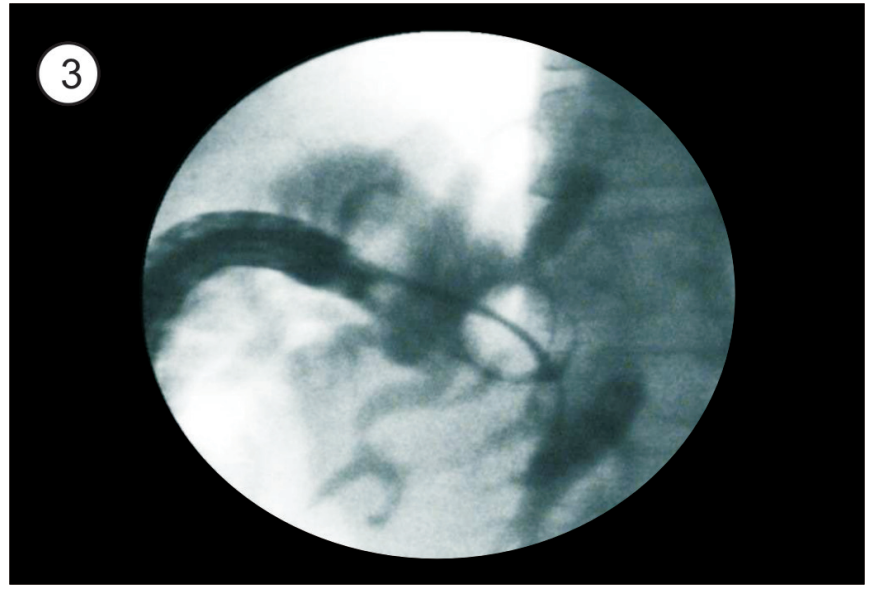

Figure 3: Endoscope introduced upto left hepatic duct showing an occlusion chonagiogram

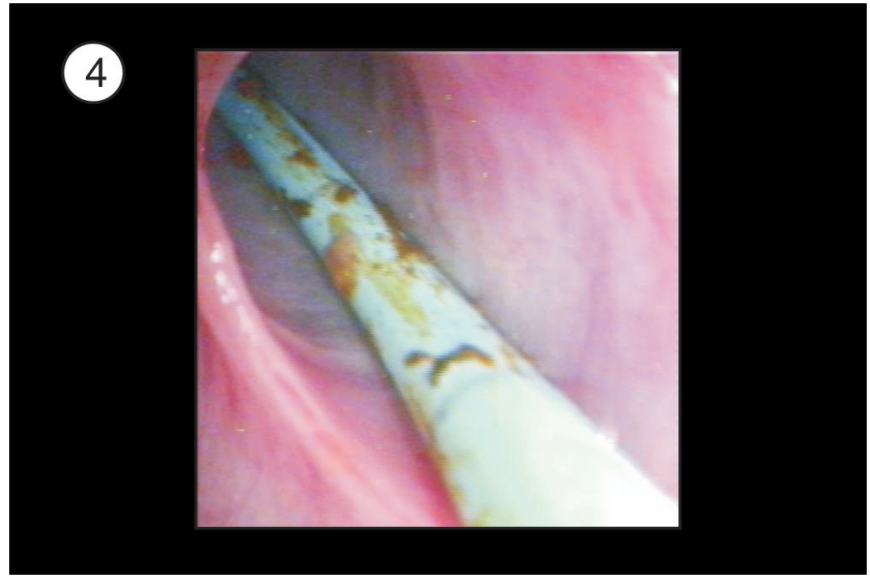

Figure 4: The balloon introduced separately into left and right hepatic duct for clearance of stones

left intrahepatic bile duct were cleared by passing a balloon with the help of a terumo wire $(0.032 \mathrm{~mm})$ into distal most part of both the ducts (Figures 3 and 4). The clearance of the biliary tract was confirmed by an occlusion cholangiogram as well as direct visualization using the UGI endoscope (Figures 5 and 6)

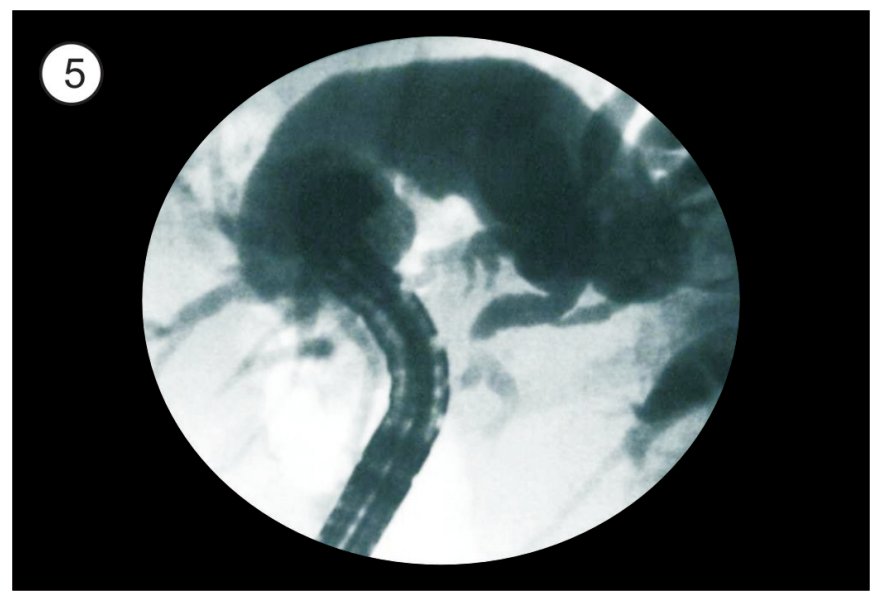

Figure 5: Normal occlusion cholangiogram of left hepatic duct after clearance of stones

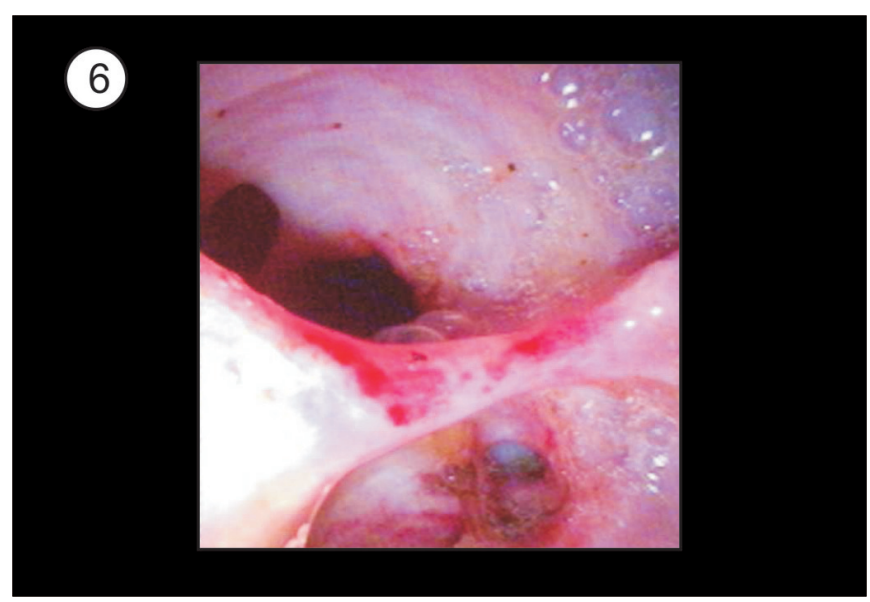

Figure 6: Normal picture of the hilum of liver after clearance of stones

This case demonstrates that recurrent stones after CDD can be successfully managed by dilatation of the stenosed CDD and clearance of stones under direct vision using an upper GI endoscope.

MALAY SHARMA

ALSHUMRANY MA

PAZHANIVEL MOHAN

Correspondence: Dr. Malay Sharma Department of Gastroenterology, ${ }^{1}$ Jaswant Rai Specialty Hospital, Meerut, India Email:sharmamalay@hotmail.com

\section{References}

1. Ueno N, Ozawa Y, Aizawa T. Prognostic factors for recurrence of bile duct stones after endoscopic treatment by sphincter dilation. Gastrointest Endosc. 2003;58:336-40.

2. Keizman D, Shalom MI, Konikoff FM. An angulated common bile duct predisposes to recurrent symptomatic bile duct stones 
after endoscopic stone extraction. Surg Endosc. 2006; 20:1594-9.

3 . Kibria SM, Hall R. Recurrent bile duct stones after transduodenal sphincteroplasty. HPB (Oxford). 2002;4:63-6.

4. Rizzutti, RP, McElwee TB, Carter JW. Choledochoduodenostomy. A safe and efficacious alternative in the treatment of biliary tract disease. Am Surg. 1987; 53:22-5.

5. Caroli-Bosc FX, Demarquay JF, Peten EP, Dumas R, Bourgeon A, Rampal P, et al. Endoscopic management of sump syndrome after choledochoduodenostomy: retrospective analysis of 30 cases. Gastrointest Endosc. 2000; 51 :180-3.

\section{Gastric teratoma: unusual location and difficulties in diagnosis}

\section{Introduction}

Gastric teratoma is an extremely rare neoplasm with only about 112 cases reported in the literature. ${ }^{1}$ These tumors usually present as exophytic masses with symptoms of obstruction and upper gastrointestinal bleeding., ${ }^{2,3}$ The clinical symptoms combined with the CT scan images usually allow for a reasonably definite pre-operative diagnosis. We report a case of gastric teratoma with no clinical indication of gastric origin. The only clue to diagnosis, in retrospect, was the mass being more anteriorly placed than expected in the CT scan images.

\section{Case report}

A 2-year-old child presented with history of a non-progressive lump in the abdomen since birth. This was accompanied by occasional colicky abdominal pain that settled spontaneously in a few minutes. There was no history of hematemesis, vomiting, early satiety or poor acceptance of feeds. Physical examination revealed fullness of the upper and central abdomen with a large palpable $16 \times 10 \mathrm{~cm}$ mass. The mass was non-tender, had an irregular surface and a variable consistency. The mass was not mobile along any axis. Based on these findings a provisional clinical diagnosis of a retroperitoneal mass, possibly a teratoma, was made. Ultrasonography revealed a large multiseptate, midline cystic mass with a soft tissue component.

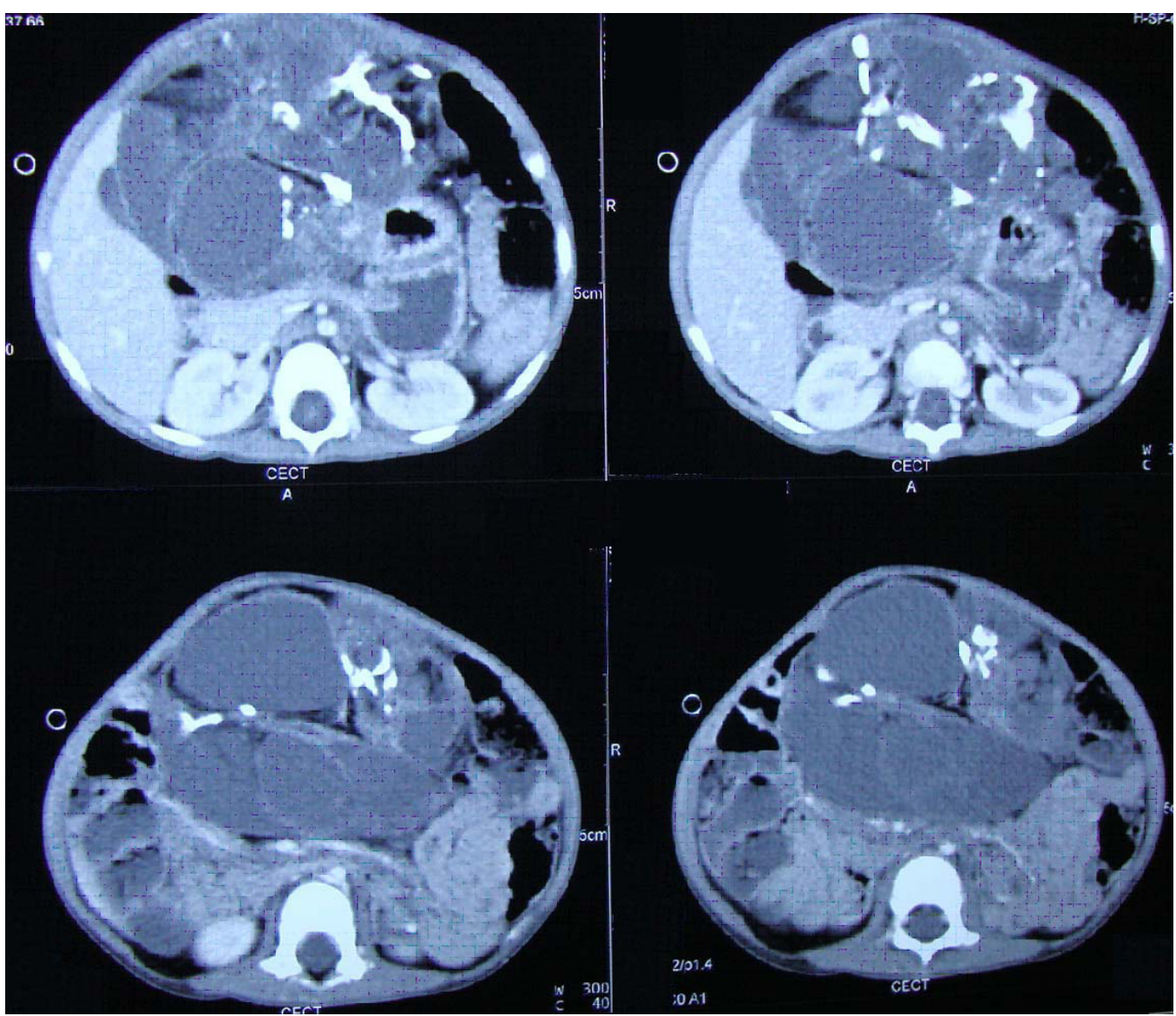

Figure 1: CECT showing a heterogenous mass with foci of calcification and soft tissue. The mass was seen to be placed anterior to the pancreas and superior mesenteric vessels. 